\title{
Vision modeling optimization of freely placed and moving objects
}

\author{
Hu Fuwen ${ }^{1,}$, $\mathrm{Li} \mathrm{Li}^{1, \mathrm{~b}}$ and He Yunhua ${ }^{2, \mathrm{c}}$ \\ ${ }^{1}$ School of Mechanical and Material Engineering, North China University of Technology, \\ Beijing 100144, China \\ ${ }^{2}$ Department of Mechanical and Electronic Engineering, Shandong University of Science and \\ Technology, Tai'an 271019, China \\ ahfw@ncut.edu.cn,b442578001@qq.com, ${ }^{\text {cbuaa001@qq.com }}$
}

Keywords: Robotic task, Machine vision, Visual feature matching, Taguchi methods

\begin{abstract}
For the intelligent operations using robots and vision sensors, it is a seemingly simple but in fact complex problem to design an efficient and accurate visual feature matching program. To determine the optimum identification pattern of freely placed and moving objects, the orthogonal experimental approach was employed. Firstly, a complex part that had eight visual features was selected as the experimental parts. Secondly, the experiment scheme was planned as a $\mathrm{L}_{12}\left(2^{11}\right)$ orthogonal array. Thirdly, the robotic handling experiments were performed. Finally, the experimental data were analyzed and the results indicated that different identification patterns of the shape and alignment would lead to different success rates, and the maximal deviation of success rates reached $60 \%$. Furthermore, according to the variance analysis the optimum identification pattern was determined.
\end{abstract}

\section{Introduction}

The rapid and effective identification of identical objects that are randomly placed in a moving platform with the help of vision equipment is still a challenging task for robotic operations. In addition to the objects' properties, the challenge becomes further complicated owing to the dynamic working environment with the production line.

Panagiota et al. [1, 2] presented a method for the identification of multiple randomly placed objects using a $2 \mathrm{D}$ vision system combined with data from computer-aided design files for the generation of 3D coordinates. João et al. [3] investigated the application of computer vision and machine learning approaches to solve a problem of feeding cork strips into drillers that move on a conveyor belt. Ashutosh et al. [4] proposed an algorithm for enabling a robot to grasp an object that it has never seen before. Their learning algorithm neither tries to build, nor requires, a 3D model of the object. Instead it predicts, directly as a function of the images, a point at which to grasp the object. Yuichi [5] developed a vision based human-robotic interaction framework for the modeling and localization of industrial objects typically found in an assembly task.

This paper presents the orthogonal experimental approach to determine the optimum identification pattern of shape and alignment of the freely placed and moving objects for robotic handling.

\section{Experimental Setup}

As shown in Fig. 1, the experimental platform includes an industrial robot of Mitsubishi RV-7F-D series, an embedded vision sensor of COGNEX insight, and a conveyor. And the experimental part is a flange part with a center hole, a hexagonal bulge and four threaded holes. This experimental platform could simulate the recognition and picking up of the objective part from the various parts freely placed on the moving conveyor belt. Obviously, in this dynamic working environment the orientation and shape of the part is random, and the area that the part moves into the real time vision is also random. Therefore, if the visual feature matching pattern is designed unreasonably, the success rate of identification is likely to be very low. In other words, owing to the 
complex working conditions and the objects' properties, the vision identification pattern should be optimized.

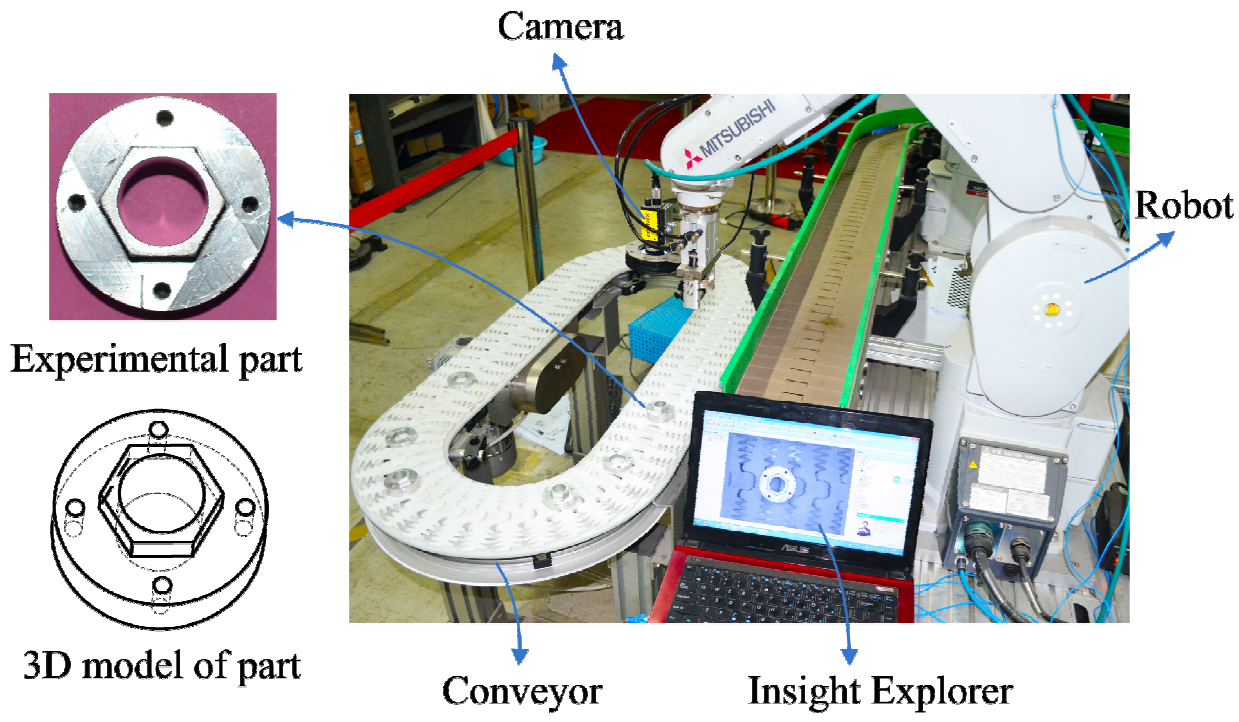

Fig. 1 Experimental setup.

\section{Orthogonal Experiment}

Orthogonal arrays (often referred to Taguchi Methods) are often employed in industrial experiments to study the effect of several control factors [6]. With respect to the experimental part, it has ten features of four holes and six corners that are marked by 1 to 10 in Fig. 2. Different combinations of these features could be the identification pattern of shape and alignment.

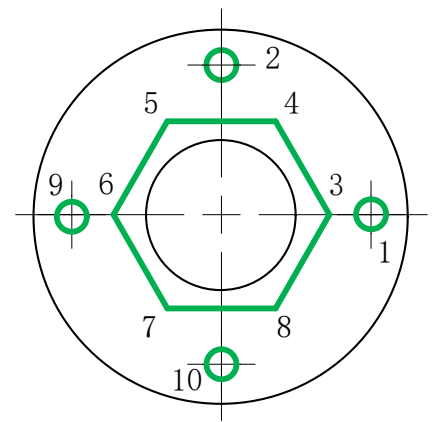

Fig. 2 Matching features.

Due to the symmetries between hole 1 and hole 9 , hole 2 and 10, there are eight factors that effect on the success rate of identification. Therefore, a two-level orthogonal array with at least 11 degree of freedom was designed. The $\mathrm{L}_{12}\left(2^{11}\right)$ orthogonal array is shown in Table 1 . The symbol $\mathrm{O}$ denotes that the feature is extracted in matching pattern. Instead, the symbol X means the feature is not used.

For each test run, we carried out twenty trials, and figured out the success rate $R_{\text {succ }}$ and average time $t$ of vision identification. Then, we used the following equation to balance their importance. And the experiments results data are listed in Table 2.

$$
E_{i}=85 R_{\text {succ }}+15 \frac{\left(t_{\max }-t\right)}{\left(t_{\max }-t_{\min }\right)}
$$


Table $1 . \mathrm{L}_{12}\left(2^{11}\right)$ Orthogonal array.

\begin{tabular}{c|c|c|c|c|c|c|c|c|c|c|c}
\hline \multirow{2}{*}{$\begin{array}{c}\text { Test } \\
\text { Run }\end{array}$} & \multicolumn{10}{|c}{ Eleven factors } \\
\cline { 2 - 14 } & 1 & 2 & 3 & 4 & 5 & 6 & 7 & 8 & 9 & 10 & 11 \\
\hline 1 & $\mathrm{O}$ & $\mathrm{O}$ & $\mathrm{O}$ & $\mathrm{O}$ & $\mathrm{O}$ & $\mathrm{O}$ & $\mathrm{O}$ & $\mathrm{O}$ & $\mathrm{O}$ & $\mathrm{O}$ & $\mathrm{O}$ \\
\hline 2 & $\mathrm{O}$ & $\mathrm{O}$ & $\mathrm{O}$ & $\mathrm{O}$ & $\mathrm{O}$ & $\mathrm{X}$ & $\mathrm{X}$ & $\mathrm{X}$ & $\mathrm{X}$ & $\mathrm{X}$ & $\mathrm{X}$ \\
\hline 3 & $\mathrm{O}$ & $\mathrm{O}$ & $\mathrm{X}$ & $\mathrm{X}$ & $\mathrm{X}$ & $\mathrm{O}$ & $\mathrm{O}$ & $\mathrm{O}$ & $\mathrm{X}$ & $\mathrm{X}$ & $\mathrm{X}$ \\
\hline 4 & $\mathrm{O}$ & $\mathrm{X}$ & $\mathrm{O}$ & $\mathrm{X}$ & $\mathrm{X}$ & $\mathrm{O}$ & $\mathrm{X}$ & $\mathrm{X}$ & $\mathrm{O}$ & $\mathrm{O}$ & $\mathrm{X}$ \\
\hline 5 & $\mathrm{O}$ & $\mathrm{X}$ & $\mathrm{X}$ & $\mathrm{O}$ & $\mathrm{X}$ & $\mathrm{X}$ & $\mathrm{O}$ & $\mathrm{X}$ & $\mathrm{O}$ & $\mathrm{X}$ & $\mathrm{O}$ \\
\hline 6 & $\mathrm{O}$ & $\mathrm{X}$ & $\mathrm{X}$ & $\mathrm{X}$ & $\mathrm{O}$ & $\mathrm{X}$ & $\mathrm{X}$ & $\mathrm{O}$ & $\mathrm{X}$ & $\mathrm{O}$ & $\mathrm{O}$ \\
\hline 7 & $\mathrm{X}$ & $\mathrm{O}$ & $\mathrm{X}$ & $\mathrm{X}$ & $\mathrm{O}$ & $\mathrm{O}$ & $\mathrm{X}$ & $\mathrm{X}$ & $\mathrm{O}$ & $\mathrm{X}$ & $\mathrm{O}$ \\
\hline 8 & $\mathrm{X}$ & $\mathrm{O}$ & $\mathrm{X}$ & $\mathrm{O}$ & $\mathrm{X}$ & $\mathrm{X}$ & $\mathrm{X}$ & $\mathrm{O}$ & $\mathrm{O}$ & $\mathrm{O}$ & $\mathrm{X}$ \\
\hline 9 & $\mathrm{X}$ & $\mathrm{O}$ & $\mathrm{O}$ & $\mathrm{X}$ & $\mathrm{X}$ & $\mathrm{X}$ & $\mathrm{O}$ & $\mathrm{X}$ & $\mathrm{X}$ & $\mathrm{O}$ & $\mathrm{O}$ \\
\hline 10 & $\mathrm{X}$ & $\mathrm{X}$ & $\mathrm{X}$ & $\mathrm{O}$ & $\mathrm{O}$ & $\mathrm{O}$ & $\mathrm{O}$ & $\mathrm{X}$ & $\mathrm{X}$ & $\mathrm{O}$ & $\mathrm{X}$ \\
\hline 11 & $\mathrm{X}$ & $\mathrm{X}$ & $\mathrm{O}$ & $\mathrm{X}$ & $\mathrm{O}$ & $\mathrm{X}$ & $\mathrm{O}$ & $\mathrm{O}$ & $\mathrm{O}$ & $\mathrm{X}$ & $\mathrm{X}$ \\
\hline 12 & $\mathrm{X}$ & $\mathrm{X}$ & $\mathrm{O}$ & $\mathrm{O}$ & $\mathrm{X}$ & $\mathrm{O}$ & $\mathrm{X}$ & $\mathrm{O}$ & $\mathrm{X}$ & $\mathrm{X}$ & $\mathrm{O}$ \\
\hline
\end{tabular}

Table 2. Experiment Data.

\begin{tabular}{c|c|c|c}
\hline Run & $R_{\text {succ }}$ & $\mathbf{t} / \mathbf{m s}$ & $E_{i}$ \\
\hline 1 & 0.75 & 263.260 & 75.189 \\
\hline 2 & 0.90 & 282.175 & 79.013 \\
\hline 3 & 0.50 & 277.665 & 47.141 \\
\hline 4 & 0.80 & 275.890 & 73.479 \\
\hline 5 & 0.60 & 277.645 & 55.651 \\
\hline 6 & 0.80 & 287.500 & 68.000 \\
\hline 7 & 0.50 & 265.815 & 52.734 \\
\hline 8 & 0.70 & 272.540 & 66.560 \\
\hline 9 & 0.65 & 271.070 & 63.004 \\
\hline 10 & 0.30 & 281.175 & 28.485 \\
\hline 11 & 0.50 & 255.715 & 57.500 \\
\hline 12 & 0.50 & 260.610 & 55.190 \\
\hline
\end{tabular}

\section{Results Discussion}

As shown in Table 2, the results indicated that different identification patterns of the shape and alignment would lead to different success rates, and the maximal deviation of success rates reached $60 \%$. Furthermore, in order to study the significance of matching features, analysis of variance (ANOVA) is performed in Table 3. ANOVA can help in formally identifying the significance of all main factors and their interactions by comparing the mean square against an estimate of the experimental errors at specific confidence levels. From Table 3 it is clear that the features of hole 1 and corner 3 have a significant impact on recognition success rate. Therefore, the optimal features of vision identification can be designed as shown in Fig. 3. 
Table 3. ANOVA results.

\begin{tabular}{c|c|c|c|c}
\hline $\begin{array}{c}\text { Source of } \\
\text { variation }\end{array}$ & $\begin{array}{c}\text { Sum of } \\
\text { squares }\end{array}$ & $\begin{array}{c}\text { Degrees of } \\
\text { freedom }\end{array}$ & Variance & F-ratio \\
\hline 1 & 468.768 & 1 & 468.768 & 6.28 \\
\hline 2 & 171.281 & 1 & 171.281 & 2.29 \\
\hline 3 & 599.315 & 1 & 599.315 & 8.03 \\
\hline 4 & 0.261 & 1 & 0.261 & 0 \\
\hline 5 & 0 & 1 & 0 & 0 \\
\hline 6 & 275.609 & 1 & 275.609 & 3.69 \\
\hline 7 & 385.395 & 1 & 385.395 & 5.16 \\
\hline 8 & 24.698 & 1 & 24.698 & 0.33 \\
\hline Error & 223.954 & 3 & 74.651 & \\
\hline Total & 2149.282 & 11 & & \\
\hline
\end{tabular}

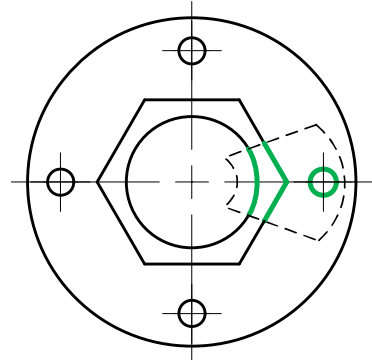

(a) Shape and orientation features

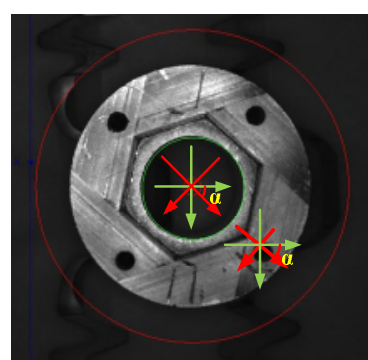

(b) Image of vision identification

Fig. 3 Optimal features of vision identification.

\section{Conclusion}

Due to the complex working conditions and the objects' properties, the vision identification system generally has the optimization space. In this work the orthogonal experimental approach was presented to determine the optimum identification pattern of shape and alignment. The experimental results indicated the optimal pattern can be found and can achieve a good effect.

\section{Reference}

[1] P. Tsarouchi, et al., Vision System for Robotic Handling of Randomly Placed Objects, Proc. Cirp. 9(4) (2013) 61-66.

[2] P. Tsarouchi, et al., A method for detection of randomly placed objects for robotic handling, Cirp. J. Manuf. Sci. Tech. 14 (2016) 20-27

[3] J. Cunha, F. Rui, N. Lau, Computer vision and robotic manipulation for automated feeding of cork drillers, Mater. Des. 82 (2015) 290-296.

[4] A. Saxena, J. Driemeyer, A. Y. Ng., Robotic grasping of novel objects using vision, Int. J. Robot. Res. 27 (2008) 157-173.

[5] Y. Motai, Salient feature extraction of industrial objects for an automated assembly system, Comput. Ind. 56(8-9) (2005) 943-957.

[6] G. P. Syrcos, Die casting process optimization using taguchi methods. J. Mater. Proc. Tech. 135 (2003) 68-74. 